\title{
Analisis Perencanaan Strategi Sistem Informasi Dalam Upaya Keunggulan Bersaing pada Apotek Kimia Farma
}

\author{
Elsaddhai $^{1}$, Augie David Manuputty ${ }^{2}$ \\ 1,2Information System Departement, Satya Wacana Christian University, Indonesia \\ E-mail: 1682017144@student.uksw.edu, 2augie.manuputty@uksw.edu
}

\begin{abstract}
In the current era, a development strategy is needed that can determine the success of all aspects of the business. If the company determines a strategy, problems will arise. In determining a business development strategy, it must be adjusted to the development of the current business situation, because even though the chosen strategy is very good, the situation and conditions are not supportive, then the strategy will fail. This study aims to develop IS / IT strategic planning in competing to increase pharmacy excellence, this research was conducted using the Ward and Peppard method and using the SWOT, Value Chain. The data taken are what factors can be strengths, weaknesses, opportunities, threats, and internal and external environmental analysis at the Kimia Farma Pharmacy Salatiga.
\end{abstract}

Keywords: Ward And Peppard , Porter's Five Forces , SWOT

\section{PENDAHULUAN}

Pada era globalisasi saat ini, sistem informasi menjadi hal penting yang mempengaruhi kehidupan manusia terutama dalam kegiatan bisnis sebuah organisasi. Untuk menghasilkan informasi yang bermanfaat, maka diperlukan data-data yang actual sebagai sumber informasi agar dapat dikelola secara baik [1]. Sistem Informasi berfungsi sebagai sarana dalam membantu organisasi untuk merealisasikan tujuan organisasi tersebut [2]. Agar Sistem tersebut dapat berfungsi secara efisien maka dibutuhkan dukungan Teknologi Informasi (TI) yang sesuai dengan kebutuhan bisnis organisasi. Sistem Informasi berbasis TI dapat menjadi sarana andalan guna memenangkan persaingan dalam industri, membantu organisasi dalam mewujudkan efisiensi, untuk meningkatkan kualitas layanan 


\section{Journal of Computer and Information Systems Ampera}

Vol. 2, No. 1, January 2021 e-ISSN: 2775-2496

https://journal-computing.org/index.php/journal-cisa/index

kepada konsumen, membantu mengambil keputusan, merencanakan ke depan, memperluas pasar, dan memasarkan produk.Keberhasilan suatu organisasi atau perusahaan sangat dipengaruhi oleh aplikasi yang digunakan maka dari itu, untuk menghadapi persaingan dewasa ini, rencana strategis organisasi harus didukung pula oleh perencanaan strategi SI/TI yang baik yang bertujuan untuk memanfaatkan secara optimum penggunaan teknologi informasi dalam memenuhi kebutuhan bisnis organisasi akan informasi. Strategi SI/TI perlu dibuat karena sumber daya yang dimiliki organisasi sangat terbatas, sehingga harus digunakan seoptimal mungkin agar dapat memberikan manfaat yang diharapkan kepada organisasi. [3]Memperbaiki daya saing atau meningkatkan keunggulan kompetitif organisasi dengan merubah gaya dan cara berbisnis.

Dalam upaya mencapai visi misi Kimia Farma Salatiga, diperlukan rencana strategis SI/TI. Pengembangan SI/TI dimaksudkan untuk mendukung tercapainya visi dan misi perusahaan serta meningkatkan keunggulan kompetitif. Selanjutnya perencanaan SI/TI dimaksudkan agar SI/TI yang dikembangkan sesuai dengan rencana strategis dan kebutuhan akan informasi di Kimia Farma. Adapun tujuan dari penelitian ini yaitu (a) membuat perencanaan strategis sistem informasi untuk meningkatkan keunggulan kompetitif dalam bersaing, (b) membuat rekomendasi sistem informasi mendatang untuk Kimia Farma.

\section{METODE}

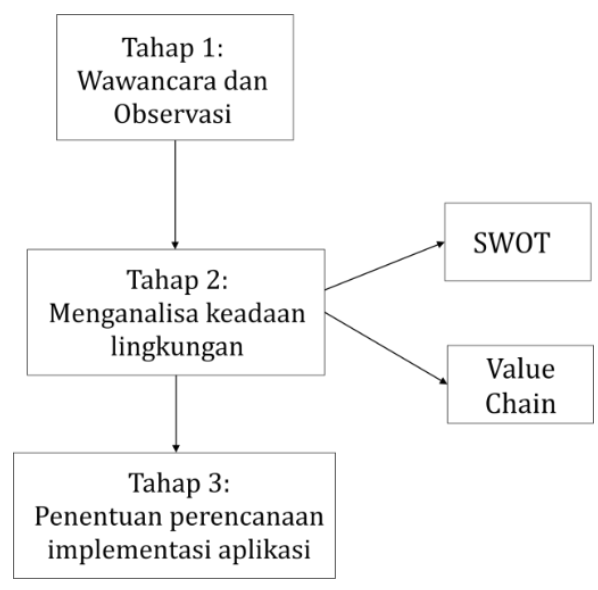

Gambar 1. Tahapan Penelitian 


\section{Journal of Computer and Information Systems Ampera}

Vol. 2, No. 1, January 2021 e-ISSN: 2775-2496

https://journal-computing.org/index.php/journal-cisa/index

\subsection{Analisis Porter's Five Forces Model}

Analisis Porter's Five Forces atau model lima faktor persaingan digunakan untuk menganalisa kondisi lingkungan eksternal yang sedang dihadapi oleh Kimia Farma Salatiga saat ini dengan menggunakan lima kekuatan bersaing yang akan menjelaskan posisi Kimia Farma Salatiga [4]. Jika dibandingkan dengan para pesaing sehingga mampu mengatasi tekanan-tekanan kompetisi di industri serta menciptakan keunggulan yang kompetitif. Adapun penjelasan mengenai analisis lima faktor persaingan atau Porter's Five Forces terhadap Kimia Farma Salatiga yakni sebagai berikut:

\section{A. Persaingan Industri (Competitive Rivalry)}

Pesaing utama Kimia Farma Salatiga adalah Apotek sejenis yang berada sewilayah dengan Kimia Farma yang mempunyai potensi berpengaruh ke penjualan Apotek Kimia Farma.

\section{B. Ancaman Pendatang Baru (Threat of New Entry)}

Ancaman pendatang baru Apotek Kimia Farma Salatiga adalah Apotek sejenis yang telah menerapkan SI/TI yang lebih mumpuni sehingga mempunyai daya saing dalam dunia marketing, maka untuk mengatasi hal tersebut Apotek Kimia Farma Salatiga harus cepat mengantisipasi hal tersebut.

\section{Kekuatan Pembeli (Buyer Power)}

Kekuatan Pembeli Apotek Kimia Farma Salatiga adalah masyarakat umum sekitar yang akan membeli obat maupun keperluan medis lainnya.

\section{Kekuatan Pemasok (Supplier Power)}

Pemasok utama Kimia Farma salatiga adalah Supplier obat atau bahan baku, alat medis, tenaga kerja, dan jasa (tenaga ahli) kepada perusahaan dapat menjadi sumber kekuatan di perusahaan, ketika ada beberapa pengganti.

\section{E. Ancaman produk pengganti (Threat of Subtitute Products)}

Apotek Kimia Farma Salatiga memprioritaskan masalah untuk dapat menciptaan keunggulan dalam menarik konsumen dibandingkan dengan pesaing dengan cara mempertahankan loyalitas pada 


\section{Journal of Computer and Information Systems Ampera}

Vol. 2, No. 1, January 2021 e-ISSN: 2775-2496

https://journal-computing.org/index.php/journal-cisa/index

konsumen dan terus meningkatkan kualitas pelayanan yang lebih unggul dibanding dengan pesaing.

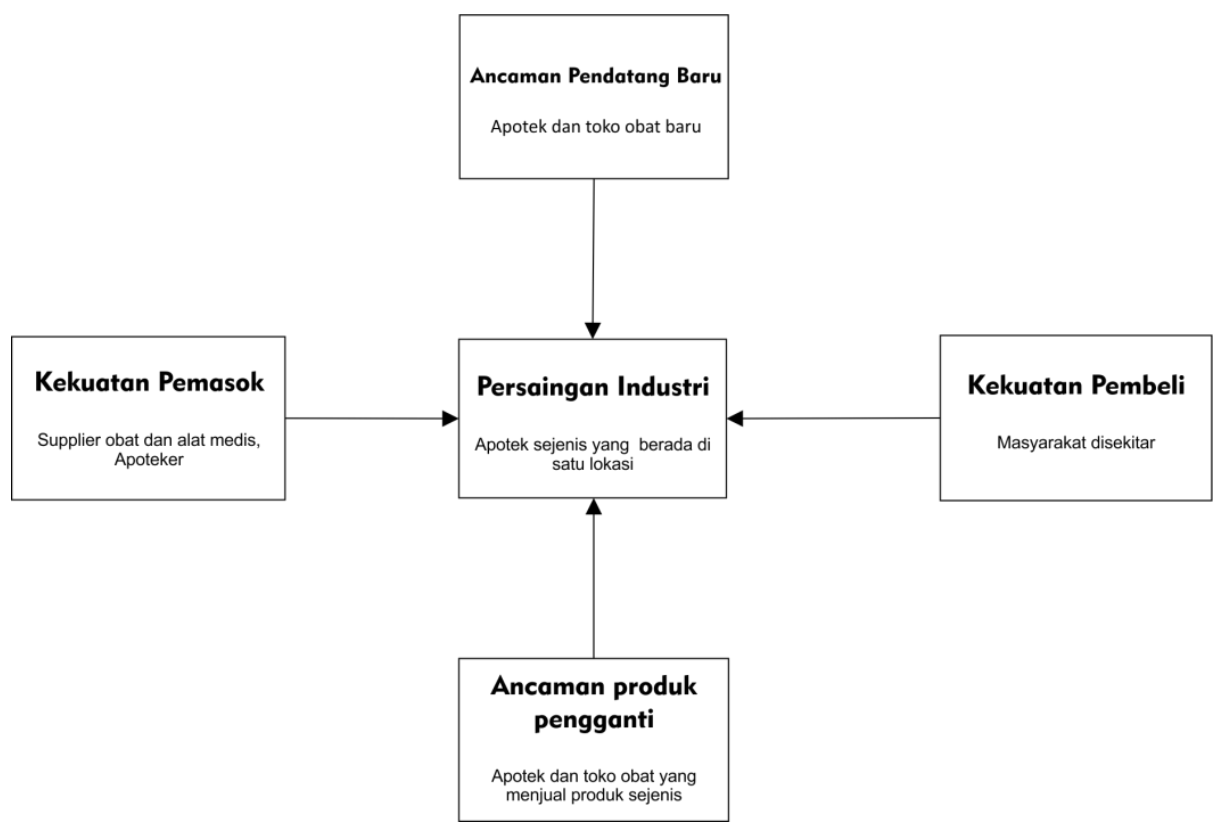

Gambar 2. Porter's Five Forces Porter di Apotek Kimia Farma Salatiga

Analisis ini merupakan perencanaan strategis SI/TI. Ward and Peppard yang terdiri dari tiga bagian. [5] Tahapan yang pertama adalah masukan (input), keluaran (output), dan aplikasi (application). Tahapan masukan ini terdiri dari lingkungan internal, lingkungan eksternal, lingkungan SI/TI internal, dan lingkungan SI/TI eksternal. Tahapan selanjutnya adalah keluaran yang terdiri dari strategis manajemen, strategis bisnis sistem informasi dan strategis teknologi informasi. Tahapan aplikasi adalah hasil dari tahapan tersebut kemudian menghasilkan portofolio aplikasi yang dapat digunakan di masa yang akan datang. Tahapan yang terakhir adalah tahapan perencanaan strategis SI/TI tersebut di dalamnya terdapat analisis yang dikembangkan oleh Ward and Peppard. Berikut gambar model perencanaan strategis SI/TI menurut Ward and Peppard : 


\section{Journal of Computer and Information Systems Ampera}

Vol. 2, No. 1, January 2021 e-ISSN: 2775-2496

https://journal-computing.org/index.php/journal-cisa/index

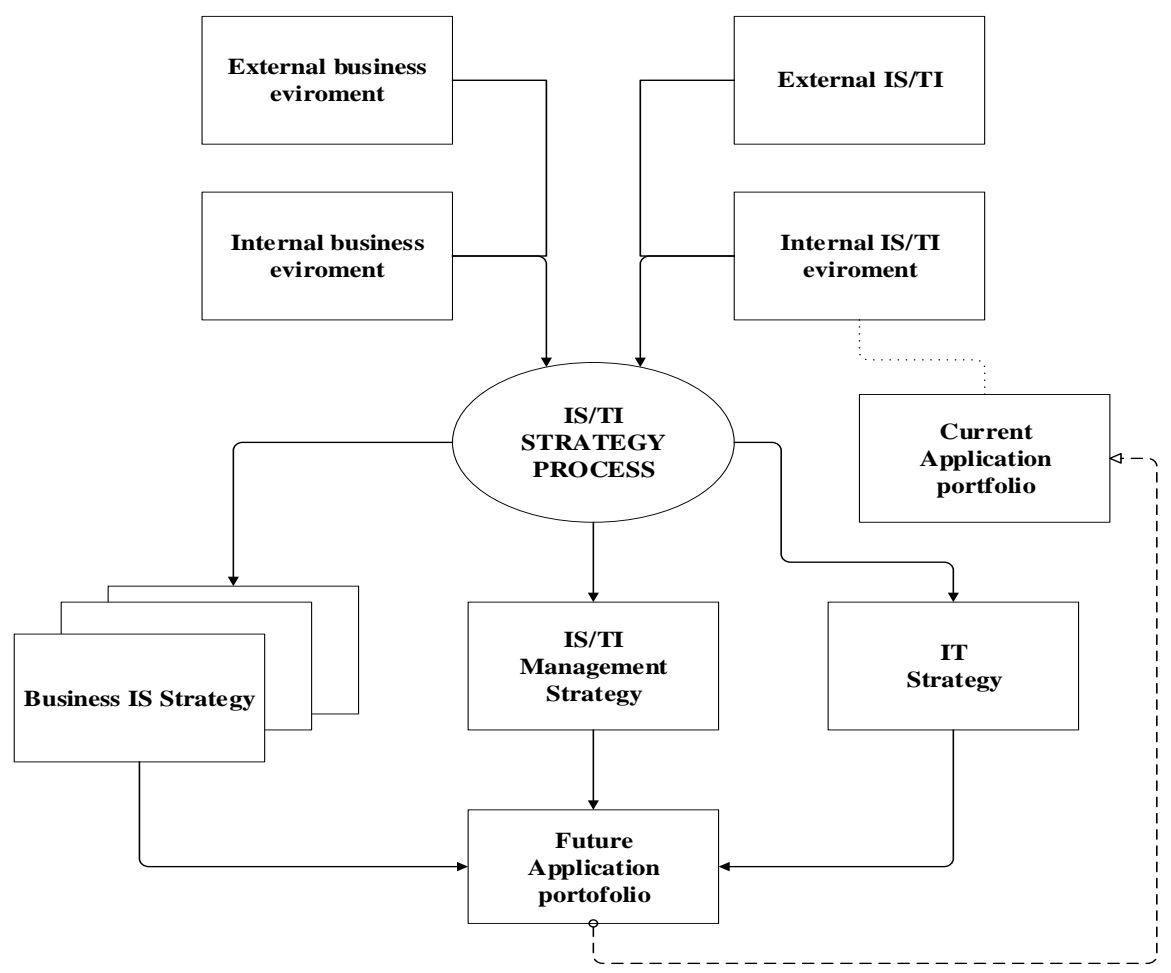

Gambar 3 Perencanaan Strategis SI/TI (Ward and Peppard 2002)

\subsection{Porter's Value Chain Analysis}

Tahap analisis yang selanjutnya adalah analisis lingkungan bisnis internal apotek untuk mengetahui proses bisnis yang terjadi di Apotek Kimia Farma Salatiga sehingga dapat memperoleh gambaran yang jelas mengenai rencana strategis sistem informasi untuk memenuhi kebutuhan Apotek. Analisis kedua yang digunakan yaitu Analisis Value Chain dilakukan untuk menggambarkan aktivitas proses bisnis utama dan proses bisnis pendukung dari Apotek Kimia Farma Salatiga, [6]Analisis Value Chain didefinisikan sebagai rantai nilai yaitu rangkaian aktivitas bisnis yang dilakukan oleh suatu perusahaan, Analisis Value Chain juga bertujuan untuk mengidentifikasi dan mengelompokkan aktivitas - aktivitas yang terjadi di Apotek ke dalam dua bagian besar yaitu aktivitas utama dan aktivitas pendukung seperti dibawah ini : 


\section{Journal of Computer and Information Systems Ampera}

Vol. 2, No. 1, January 2021 e-ISSN: 2775-2496

https://journal-computing.org/index.php/journal-cisa/index

Aktivitas utama:

1. Distribusi dan Perdagangan alat medis sebagai distributor dari PT. Kimia Farma Tbk.

2. Ritel Farmasi sebagai perusahaan yang bergerak di bidang ritel produk kesehatan.

3. Layanan Kesehatan yang disediakan termasuk sebagai aktivitas utama yang ada di Kimia Farma.

Aktivitas Pendukung:

1. Pengelolaan keuangan dan stok barang merupakan aktivitas pendukung yang dilakukan oleh Kimia Farma sebagai kewajiban untuk membuat laporan ke pusat.

2. Pengelolaan SDM dan sarana prasarana merupakan kegiatan yang mendukung proses bisnis Kimia Farma agar tetap bisa menjaga kualitas mereka.

3. Pengelolaan laporan penjualan dilakukan untuk mengatur segala stok barang yang ada di Kimia Farma.

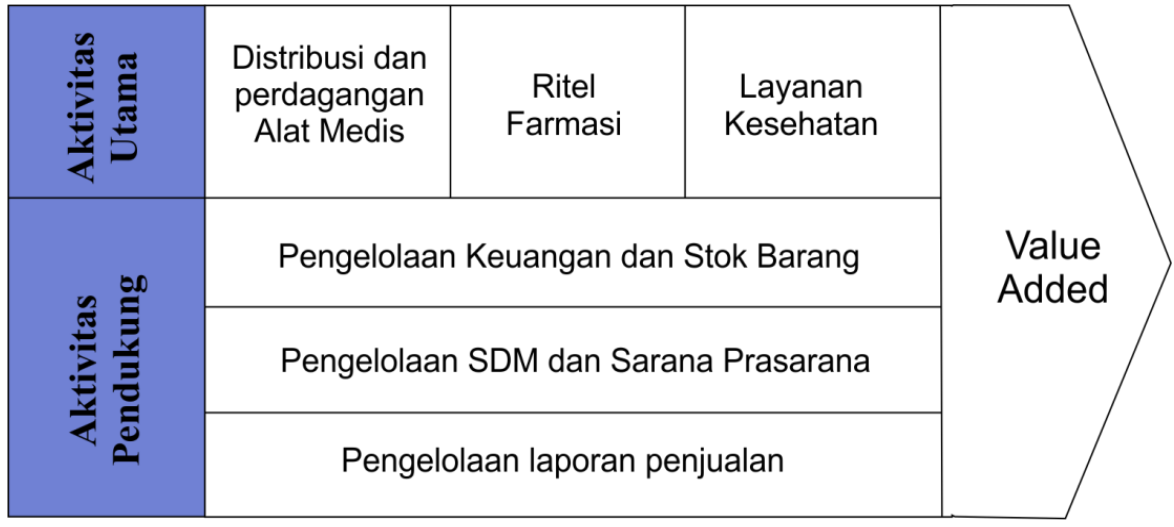

Gambar 4. Porter's Value Chain Analysis di Apotek Kimia Farma Salatiga

\subsection{Analisis SWOT}

Analisis SWOT adalah metode perencanaan strategis yang digunakan untuk mengevaluasi kekuatan (strengths), kelemahan (weaknesses), peluang (opportunities), dan ancaman (threats) dalam suatu proyek atau bisnis [7]. Analisis SWOT digunakan untuk menganalisis kondisi bisnis dan SI/TI Kimia Farma secara internal maupun eksternal. 


\section{Journal of Computer and Information Systems Ampera}

Vol. 2, No. 1, January 2021 e-ISSN: 2775-2496

https://journal-computing.org/index.php/journal-cisa/index

\section{A. Analisis Lingkungan Internal Apotek}

Analisis lingkungan internal didapatkan dari kekuatan (strengths) dan kelemahan (weakness) yang dimiliki oleh Apotek Kimia Farma

- Kekuatan (Strengths)

1. Memiliki Sumber Daya Manusia yang mendukung aktivitas bisnis yang ada

2. Developer aplikasi ditangani langsung oleh Telkom

3. Evaluasi kinerja pegawai yang dilakukan secara berkala

- Kelemahan (Weakness)

1. Kurangnya SDM pada bidang IT

2.Tidak adanya backup pada penjualan jika terjadi kerusakan sistem

\section{B. Analisis Lingkungan Eksternal Kimia Farma}

Analisis lingkungan eksternal didapatkan dari peluang (opportunities)

dan ancaman (threat).

\section{- Peluang (Opportunities)}

1.Luasnya ruang lingkup pemasaran sehingga tujuan dari bisnis dapat tercapai

2.Kinerja pegawai yang di evaluasi secara rutin dapat meningkatkan nilai Stakeholder

- Ancaman (Threats)

1. Banyaknya pesaing dibidang sejenis.

2. Pesaing lebih maju dalam hal marketing.

\section{HASIL DAN PEMBAHASAN}

\subsection{Profil Kimia Farma}

\section{VISI}

1. Menjadi perusahaan Healthcare pilihan utama yang terintegrasi dan menghasilkan nilai yang berkesinambungan.

\section{MISI}

1. Melakukan aktivitas usaha di bidang-bidang industri kimia dan farmasi, perdagangan dan jaringan distribusi, ritel farmasi dan layanan kesehatan serta optimalisasi aset.

2. Mengelola perusahaan secara Good Corporate Governance dan operational excellence didukung oleh Sumber Daya Manusia (SDM) profesional.

3. Memberikan nilai tambah dan manfaat bagi seluruh stakeholder. 


\section{Journal of Computer and Information Systems Ampera}

Vol. 2, No. 1, January 2021 e-ISSN: 2775-2496

https://journal-computing.org/index.php/journal-cisa/index

Berdasarkan hasil dari Analisa SWOT diatas dapat disimpulkan untuk menyusun perencanaan strategis sistem informasi manajemen di Apotek Kimia Farma Salatiga sebagai berikut:

A. Mengembangkan kekuatan dan memaksimalkan peluang (S-0)

1. Apotek memiliki sistem yang didevelope langsung oleh Telkom dan ada pengecekan secara berkala dari developer, sehingga Apotek kimia Farma sudah unggul dalam penjualan online.

2. Apotek memiliki SDM yang mumpuni dan selalu dievaluasi untuk menunjang aktivitas bisnisnya, sehingga proses bisnis dapat berjalan dengan baik.

B. Mengembangkan kekuatan dengan mengurangi ancaman (S-T)

1. Apotek dapat menggunakan SDM dari Telkom untuk membuat aplikasi agar memudahkan kinerja karyawan yang masih dilakukan secara manual.

C. Meminimalkan kelemahan untuk memanfaatkan peluang (W-0)

1. Apotek harus lebih meningkatkan kinerja dan keamanan aplikasi yang ada saat ini agar pengelolaan bisnisnya lebih berjalan baik dengan kualitas apotek yang semakin meningkat.

D. Meminimalkan kelemahan dan menghindari ancaman (W-T)

1. Apotek bekerja sama dengan Telkom sebagai developer aplikasi dan sistem yang ada di Apotek Kimia Farma, sehingga apotek dapat lebih unggul dalam bersaing dengan apotek lainnya.

2. Apotek dapat mengembangkan sumber daya manusia serta sarana-prasarana dengan cara menambah dan mengevaluasi sehingga dalam lingkungan bisnis dapat terus berkembang serta kualitas sumber daya manusia dalam bidang kesehatan meningkat.

\section{E. Analisis Lingkungan SI/TI Sekolah}

Dalam melakukan identifikasi sistem informasi di Apotek Kimia Farm Salatiga, maka dilakukan analisis lingkungan SI/TI secara internal menggunakan sistem informasi dan teknologi informasi yang 


\section{Journal of Computer and Information Systems Ampera}

Vol. 2, No. 1, January 2021 e-ISSN: 2775-2496

https://journal-computing.org/index.php/journal-cisa/index

tersedia. Sistem informasi yang digunakan berbentuk aplikasi ataupun perangkat keras, status aplikasi dan sumber daya manusia yang digunakan sebagai pengguna sistem informasi manajemen yang terdapat di Apotek Kimia Farma Salatiga. Adapun daftar sistem informasi yang digunakan oleh Apotek Kimia Farma Salatiga saat ini seperti pada Tabel $1 \mathrm{di}$ bawah ini:

Tabel 1. Daftar Sistem Informasi di Apotek Kimia Farma Salatiga

\begin{tabular}{|c|c|c|c|c|}
\hline & $\begin{array}{l}\text { Nama Sistem } \\
\text { Informasi }\end{array}$ & Pengguna & Status & $\begin{array}{l}\text { Jenis } \\
\text { Aplikas }\end{array}$ \\
\hline 1. & KIS & PA Farmasi & Terintegrasi & $\begin{array}{c}\text { Desktop } \\
\text { dan } \\
\text { Mobile }\end{array}$ \\
\hline 2. & POS & $\begin{array}{c}\text { Asisten Apoteker, } \\
\text { Apoteker, Pharmasi } \\
\text { Manager }\end{array}$ & Terintegrasi & $\begin{array}{l}\text { Web } \\
\text { App }\end{array}$ \\
\hline 3. & Smart Stock & $\begin{array}{l}\text { Pharmasi Manager, } \\
\text { Asisten Apoteker }\end{array}$ & Terintegrasi & Desktop \\
\hline
\end{tabular}

Berdasarkan hasil analisis yang diperoleh dari tahapan yang ada diatas yaitu analisis proses SI/TI Apotek Kimia Farma Salatiga baik lingkungan internal maupun eksternal. Berikut beberapa pengembangan aplikasi sistem informasi yang dapat diusulkan berdasarkan hasil analisis sebagai berikut :

1) AllCube adalah aplikasi untuk mengumpulkan semua data yang ada dari ketiga aplikasi tersebut.

2) SendToUS adalah aplikasi untuk mengirim laporan ke pusat secara otomatis jika semua proses pengumpulan selesai.

3) SmartStock adalah aplikasi yang digunakan untuk melihat persediaan barang yang dijual, aplikasi ini perlu diupdate dengan fitur tambahan seperti adanya sistem laporan otomatis yang terintegrasi ke SendToUs.

Usulan strategi sistem informasi untuk Apotek Kimia Farma Salatiga, dapat disusun seperti pada Tabel 2 berikut. 
Journal of Computer and Information Systems Ampera

Vol. 2, No. 1, January 2021 e-ISSN: 2775-2496

https://journal-computing.org/index.php/journal-cisa/index

Tabel 2. Daftar Sistem Informasi Usulan

\begin{tabular}{ccccc}
\hline No & $\begin{array}{c}\text { Nama Sistem } \\
\text { Informasi }\end{array}$ & Pengguna & Status & $\begin{array}{c}\text { Jenis } \\
\text { Aplikasi }\end{array}$ \\
\hline \multirow{4}{*}{ AllCube } & $\begin{array}{c}\text { Pharmasi } \\
\text { Manager, Asisten } \\
\text { Apoteker, } \\
\text { Apoteker }\end{array}$ & $\begin{array}{c}\text { Baru dan Belum } \\
\text { diimplementasikan }\end{array}$ & $\begin{array}{c}\text { Desktop, } \\
\text { Mobile }\end{array}$ \\
& & $\begin{array}{c}\text { Pharmasi } \\
\text { Manager }\end{array}$ & $\begin{array}{c}\text { Baru dan Belum } \\
\text { diimplementasikan }\end{array}$ & $\begin{array}{c}\text { Desktop, } \\
\text { Mobile }\end{array}$ \\
2 & SendToUs & $\begin{array}{c}\text { Pharmasi } \\
\text { Manager, Asisten } \\
\text { Apoteker }\end{array}$ & $\begin{array}{c}\text { Lama dan perlu } \\
\text { diperbaharui }\end{array}$ & Desktop \\
\hline
\end{tabular}

\section{KESIMPULAN}

Dari seluruh proses yang dilakukan dalam penelitian ini, sistem laporan yang ada di Kimia Farma harus langsung terintegrasi langsung dengan ketiga aplikasi yang ada saat ini agar semua proses laopran dapat dilakukan secara otomatis guna mengurangi waktu yang dibutuhkan untuk mengupload laporan ke pusat. Demi melancarkan segala aktivitas yang ada maka telah diusulkan aplikasi untuk menunjang proses tersebut, yakni: AllCube dan SendToUS. Hasil penelitian ini diharapkan dapat digunakan oleh Kimia Farma sebagai pertimbangan menentukan strategi yang tepat agar bisa berkompetitif dengan apotek yang lain.

\section{DAFTAR PUSTAKA}

[1] N. D. Retnowati, "Penerapan Sistem Informasi Menggunakan Analisis Value Chain Studi Kasus: PT Intan Pariwara Klaten," J. Buana Inform., vol. 2, no. 2, pp. 73-80, 2011, doi: 10.24002/jbi.v2i2.310.

[2] Y. Utami, A. Nugroho, and A. F. Wijaya, "Perencanaan Strategis Sistem Informasi dan Teknologi Informasi pada Dinas Perindustrian dan Tenaga Kerja Kota Salatiga," J. Teknol. Inf. dan Ilmu Komput., vol. 5, no. 3, p. 253, 2018, doi: 10.25126/jtiik.201853655.

[3] Ari Wedhasmara, "LANGKAH-LANGKAH PERENCANAAN STRATEGIS SISTEM INFORMASI DENGAN MENGGUNAKAN 


\section{Journal of Computer and Information Systems Ampera}

Vol. 2, No. 1, January 2021 e-ISSN: 2775-2496

https://journal-computing.org/index.php/journal-cisa/index

METODE WARD AND PEPPARD | Wedhasmara | Jurnal Sistem Informasi," Jsi, vol. VOL. 1, NO, no. 1, pp. 14-22, 2017, [Online]. Available:

https://ejournal.unsri.ac.id/index.php/jsi/article/view/704.

[4] A. Heriadi, M. Suyanto, and S. Sudarmawan, "Perencanaan Strategis Sistem Informasi STMIK Cahaya Surya Kediri," Creat. Inf. Technol. J., vol. 1, no. 1, p. 15, 2015, doi: 10.24076/citec.2013v1i1.6.

[5] F. Wibowo and A. F. Wijaya, "Perencanaan Strategis SI/TI Menggunakan Metode Ward and Peppard (Studi Kasus: Sinode GKJ)," Semin. Nas. Sist. Inf. Indones., no. November, pp. 39-44, 2018.

[6] Kementerian Kesehatan Republik Indonesia, “No 主観的健康感を 中心とした在宅高齢者における 健康関連指標に関する共分散構 造分析Title," no. June, 2016.

[7] G. R. Dantes et al., "INFORMASI ( Studi Kasus : PT . BPR Jaya Kerti )," no. 1, pp. 32-43, 2018. 